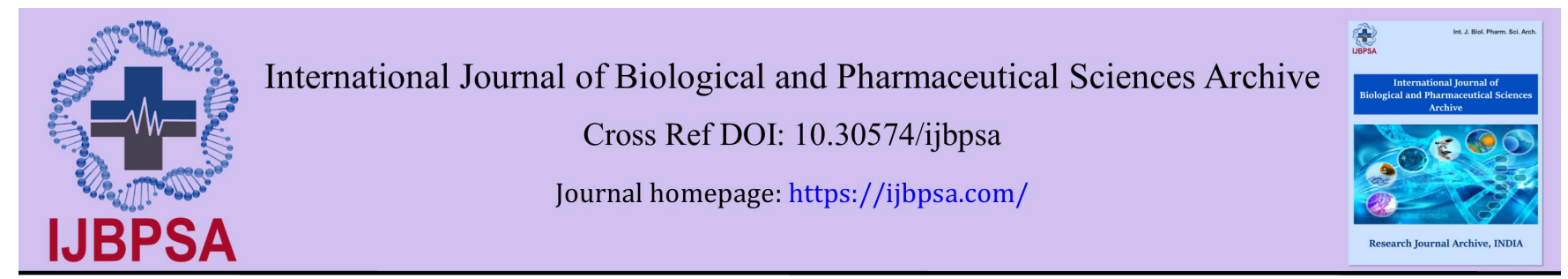

(REVIEW ARTICLE)

\title{
Natural products targeting the p53 tumor suppressor-A novel approach for future cancer therapy- A review
}

\author{
Ali Esmail Al-Snafi * \\ Department of Pharmacology, College of Medicine, University of Thi-Qar, Iraq. \\ International Journal of Biological and Pharmaceutical Sciences Archive, 2021, 01(02), 167-176 \\ Publication history: Received on 22 April 2021; revised on 26 May 2021; accepted on 29 May 2021
}

Article DOI: https://doi.org/10.30574/ijbpsa.2021.1.2.0044

\begin{abstract}
Mutations of $\mathrm{p} 53$, a tumor suppressor gene, are known to be involved in multiplication and metastasis of tumors. A number of natural products targeted the p53-MDM2 pathway. This review is an attempt to highlight the medicinal plants that can modulate the expression and activity ofp53tumor suppression, for cancer prevention and treatment.
\end{abstract}

Keywords: Tumor multiplication; Tumor metastasis; Natural; P53;Medicinal plants

\section{Introduction}

Human cancer is associated with alterations in a number of oncogenes and tumor suppressor genes that occur at various stages, from carcinogenesis to tumor growth, progression and metastasis.Proto-oncogenes normally control cell division and growth; molecular alterations, including gain-of-function mutations, amplification, and overexpression, can trigger the activation of oncogenes, leading to uncontrolled cell division, finally causing cancer [1-3].

Thep53 protein was identified in 1979. The human p53 gene is located on the seventeenth chromosome. The p53 tumor suppressor gene is the most frequently mutated gene in human cancer. The p53 protein is a phosphoprotein made of 393 amino acids. which grouped into six domains: a- the N-terminal region consists of the Transcription Activation Domain (TAD), which subdivided into two regions (TD ${ }_{1}$ and TD2), b- the Proline-Rich Region (PRR), which is constant in themajority of p53s, c- the central core domain (p53C), where the DNA-binding part is located and more than $90 \%$ of human mutations take place, $d$ - the nuclear localization signal domain, e- the tetramerization (TET) domain, and e- the C-terminal domain (CT), which is the nonspecific DNA-binding domain [4-7].

Several signals can generate p53 within minutes, included ultraviolet radiation, and hypoxia, blockage of transcription, oncogene signaling, ionizing radiation, and lack of nucleotides. Then, p53 will induce cell cycle arrest, and apoptosis and block angiogenesis and DNA repair [8]. Ithas a number of other functions that recent data strongly implicate in tumor suppression, particularly with regard to the control of metabolism and ferroptosis (iron- and lipid-peroxide-mediated cell death) by p53. Wild-type (WT) p53 negatively regulates lipid synthesis and glycolysis in normal and tumor cells, and positively regulates oxidative phosphorylation and lipid catabolism. Mutant p53 in tumor cells does the converse, positively regulating lipid synthesis and glycolysis. The role of p53 in ferroptosis is even more complex: in normal tissues, WT p53 appears to positively regulate ferroptosis, and this pathway appears to play a role in the ability of basal, unstressed p53 to suppress tumor initiation and development [9-12]. In-vitro introduction of p53 in to p53-deficient cells has been shown to cause rapid death of cancer cells or prevention of further division. Various strategies have been proposed to restore p53 function in cancer cells [13]. The p53-MDM2 interactions have become the cornerstone of intensive cancer based research due to their effective anti-cancerproperties [14].This mini review is an attempt to highlight the medicinal plants that can modulate the expression and activity ofp53tumor suppressor.

${ }^{*}$ Corresponding author: Ali Esmail Al-Snafi

Department of Pharmacology, College of Medicine, University of Thi-Qar, Iraq.

Copyright $(2021$ Author(s) retain the copyright of this article. This article is published under the terms of the Creative Commons Attribution Liscense 4.0. 


\section{Medicinal plants modulated the expression and activity ofp53tumor suppressor}

\subsection{Allium sativum}

The antiproliferative effects of diallyl sulfide (DAS), diallyl disulfide (DADS) and garlic extract were investigated on p53wild type $\mathrm{H} 460$ and p53-null type H1299 non-small cell lung cancer cells (NSCLC). The DAS and DADS treatment of both H460 and H1299 cells resulted in the highest numbers of cells in apoptotic state as measured by acridine orange staining. DADS was found to be more effective in inducing apoptosis on NSCLC. The level of p53 protein in H460 cell was increased following DADS treatment. DAS and garlic extract treatment of H460 cells induced a rise in the level of Bax and a fall of Bcl-2 level [15-16].

\subsection{Calendula Species}

The hepatoprotective effect of calendula flowers and/or thyme leave extracts on aflatoxins (AFs)-induced oxidative stress, genotoxicity and alteration of p53 bax and bcl2 gene expressions were evaluated. Animals treated with the extracts 1 week before AFs treatment showed a significant decrease in oxidative damage markers, micro nucleated cells, DNA fragmentation and modulation of the expression of pro-apoptotic genes [17-18].

\subsection{Capsicum Species}

The effects of capsaicin on leukemic cells in vitro and in vivo and the molecular mechanisms of capsaicin-induced apoptosis were investigated in myeloid leukemic cells. Capsaicin suppressed the growth of leukemic cells, but not normal bone marrow mononuclear cells, via induction of G0-G1 phase cell cycle arrest and apoptosis. Capsaicin-induced apoptosis was in association with the elevation of intracellular reactive oxygen species production. Interestingly, capsaicin-sensitive leukemic cells were possessed of wild-type p53, resulting in the phosphorylation of p53 at the Ser15 residue by the treatment of capsaicin. Abrogation of p53 expression by the antisense oligonucleotides significantly attenuated capsaicin-induced cell cycle arrest and apoptosis [19-20].

\subsection{Carthamus tinctorius}

The mechanism of regulating HIF-1alpha expression by hydroxysafflor yellow A (HSYA) in Eahy 926 cell line under $1 \%$ 02 hypoxia was studied. Eahy 926 cells were incubated with HSYA (100, 10 and 1 micromol x l-1) under hypoxia for the indicated time after treatment. HSYA at 100 micromol x l-1 increased Eahy 926 cells proliferation rate under hypoxia. HIF-1alpha mRNA and protein expression were up-regulated in the presence of HSYA. VHL, p53 mRNA and protein expression decreased significantly after 8 hours of treatment under hypoxia. Accordingly, HSYA protected Eahy 926 cells from hypoxia, and up-regulated HIF-1alpha expression partially via its inhibition of VHL and p53 expression [2122].

\subsection{Catha edulis}

Catha edulis possessedp53 induction and cell cycle arrest, decreased mitochondrial function and activation of receptorand mitochondria-mediated cell death pathways. Experiments using a p53 knock-down cell line and murine p53 knockout bone marrow cells indicated that p53 was redundant in Catha edulis-mediated cell death in vitro [23].

\subsection{Citrus aurantifolia}

The bioactive compounds isolated from the seeds of Citrus aurantifolia were found to possess the potential of inhibiting human pancreatic cancer cells. While, the compounds purified from peel had the potential of suppressing the colon cancer cells. The purified compounds from seeds exhibited significant inhibition of Panc-28 cells with IC $\mathrm{C}_{50}$ values in the range of 18.1-100 $\mu \mathrm{M}$, which was confirmed by viable cell count. DNA fragmentation and expression of proteins in cells treated with compounds showed the induction of apoptosis through p53 and caspase-3 mediated pathway. The volatile oil showed 78 per cent inhibition of human colon cancer cells (SW-480) with $100 \mu \mathrm{g} / \mathrm{ml}$ concentration at $48 \mathrm{~h}$. Lime volatile oil showed DNA fragmentation and induction of caspase- 3 up to 1.8 and two folds after 24 and $48 \mathrm{~h}$, respectively [24-25].

\subsection{Corchorus Species}

The effects of Saikosaponin-A on human breast cancer cell lines (MDA-MB-231 and MCF-7) were investigated. Results demonstrated that Saikosaponin-A inhibited the proliferation or viability of the MDA-MB-231 and MCF-7 cells in a dosedependent manner. Saikosaponin-A treatment of MDA-MB-231 for 3 hours and of MCF-7 cells for 2 hours, respectively caused an obvious increase in the sub-G1 population of cell cycles. Apoptosis in MDA-MB-231 cells was independent of the P53/p21 pathway mechanism and was accompanied by an increased ratio of Bax to Bcl-2 and c-myc levels and 
activation of caspase-3. In contrast, apoptosis of MCF-7 cells was initiated by the Bcl-2 family of proteins and involved p53/p21 dependent pathway mechanism, and was accompanied by an increased level of c-myc protein [26-27].

\subsection{Crocus sativus}

In order to examine saffron's anti-proliferative and pro-apoptotic effects in colorectal cancer cells, two p53 isogenic HCT116 cell lines (HCT wildtype and HCT p53-/-)were treated with different doses of the drug and analyzed cell proliferation and apoptosis in a time-dependent manner. Saffron extract induced a p53-dependent pattern of cell cycle distribution with a full G2/M stop in HCT116 p53 wildtype cells. However, it induced a remarkable delay in S/G2 phase transit with entry into mitosis in HCT116 p53 -/- cells. The apoptotic Pre-G1 cell fraction as well as Annexin V staining and caspase 3 cleavage showed a more pronounced apoptosis induction in HCT116 p53 wildtype cells. Obviously, the significantly higher DNA-damage, reflected by $\mathrm{\gamma}_{\mathrm{H}} \mathrm{AXX}$ protein levels in cells lacking p53, was coped by up-regulation of autophagy. The saffron-induced LC3-II protein level was a remarkable indication of the accumulation of autophagosomes, a response to the cellular stress condition of drug treatment [28-29].

MTT assay was performed to detect the inhibitory action of crocin on the proliferation of ovarian cancer H0-8910 cells. Flow cytometry was used to test the cell cycle distribution and apoptosis rate of ovarian cancer H0-8910 cells. Western blot analysis was utilized to measure the levels of apoptotic proteins such as p53, Fas/AP0-1, and Caspase-3. MTT analysis revealed that crocin significantly inhibited the growth of HO-8910 cells. Additionally, flow cytometry illustrated that crocin raised the proportion of HO-8910 cells in the G0/G1 phase and increased their apoptosis rate. Furthermore, Western blot analysis revealed that crocin up-regulated the expression of p53, Fas/APO-1, and Caspase-3.Accordingly, crocin significantly inhibited the growth of HO-8910 cells and arrest them in the G0/G1 phase. Crocin also promoted ovarian cancer HO-8910 cell apoptosis, most likely by increasing p53 and Fas/APO-1 expression, and activating the apoptotic pathway regulated by Caspase-3 [30].

\subsection{Curcuma longa}

Curcumin $50 \mu \mathrm{g} / \mathrm{kg}$ and $200 \mu \mathrm{g} / \mathrm{kg}(\mathrm{ip})$ every other day for 28 days, and diet containing curcumin at $0.6 \%$; possessed antiproliferative effects and increased apoptosis and p53 expression in mice bearing malignant breast tumors [31-32].

\subsection{Daucus carota}

The anticancer activity of the pentane fraction (F1) and the 1:1 pentane: diethyl ether fraction (F2) of the Daucus carota oil extract was evaluated against human colon adenocarcinoma cell lines (HT-29 and Caco-2). Treatment of cells with various concentrations of F1 or F2 fractions produced a dose-dependent inhibition of cell proliferation. Flow cytometric analysis indicated that both fractions induced sub-G1 phase accumulation and increased apoptotic cell death. Western blot revealed the activation of caspase-3, PARP cleavage, and a considerable increase in Bax and p53 levels, and a decrease in Bcl-2 level. Treatment of HT-29 cells with either fraction markedly decreased the levels of both phosphorylated Erk and Akt [33-34].

\subsection{Digitalis Species}

Regarding the mechanisms of anticancer effects of cardiac glycosides, it appeared that digitoxin induced cell cycle arrest in G2/M phase via down-regulation of cyclin B1, cdc2 and surviving and increased the intracellular Ca ${ }^{2+}$ concentration. Digoxin increased intracellular $\mathrm{Ca}^{2+}$ concentration and induced DNA topoisomerases I and II and induced cell cycle arrest via the up-regulation of HIF- $1 \alpha$. Ouabaindepleted $\mathrm{Na}^{+} / \mathrm{K}^{+}$- ATPase and up-regulated p21, increased intracellular $\mathrm{Ca}^{2+}$ concentration and inhibited DNA topoisomerases I and II. Oleandrin attenuated NF-kB, JNK and AP-1activation. Bufalin induced cell cycle arrest in G2/M phase via up-regulation of p21 WAF1 and p53 and the down-regulation of cyclin D, and inhibitedDNA topoisomerases I and II. Proscillaridin A, inhibited DNA topoisomerases I and II andincreasedintracellular $\mathrm{Ca}^{2+}[35-36]$.

\subsection{Eucalyptus Species}

Anticancer activities of $p$-menth-1-ene-4,7-diol (EC-1) isolated from Eucalyptus camaldulensis were studied on Ehrlich ascites carcinoma (EAC) cells. Anticancer activities also analyzed in EAC-bearing mice by assessment of cancer growth inhibition, changes in cancer volume, changes in life span, and hematological parameters. Apoptosis was analyzed by fluorescence microscope, DNA fragmentation assay, and flow cytometry. The expression of apoptosis-related genes, $\mathrm{Bcl}$ 2, Bcl-X, PARP-1, p53, and Bax, were analyzed using polymerase chain reaction (PCR).P-menth-1-ene-4, 7-diol (EC1)significantly inhibited proliferation of EAC cells in vivo and restored the altered hematological parameters of EACbearing mice. Cytological observation by fluorescence microscope showed apoptosis of EAC cells upon treatment with EC-1. Also, DNA fragmentation assay revealed EAC cells' apoptosis following EC-1 treatment. Increased mRNA 
expressions of p53 and Bax genes and negative expressions of Bcl-2 and Bcl-Xwere observed in cells treated with EC1.MTT assay showed dose-dependent anticancer activity of EC-1 against EAC cell. Cell cycle analysis revealed that EC-1 treatment caused suppression of EAC cells at S phase [37-38].

\subsection{Ficus religiosa}

The anti-neoplastic potential of aqueous extract of Ficus religiosa bark was studiedin human cervical cancer cell lines, $\mathrm{SiHa}$ and HeLa. The aqueous extract ofFicus religiosa altered the growth kinetics of SiHa (HPV-16 positive) and HeLa (HPV-18 positive) cells in a dose-dependent manner. It blocked the cell cycle progression at G1/S phase in SiHa that was characterized by an increase in the expression of p53, p21 and pRb proteins with a simultaneous decrease in the expression of phospho $\mathrm{Rb}(\mathrm{ppRb})$ protein. In HeLa, aqueous extract of Ficus religiosa induced apoptosis through an increase in intracellular $\mathrm{Ca}^{2+}$ leading to loss of mitochondrial membrane potential, release of cytochrome-c and increase in the expression of caspase-3. The aqueous extract ofFicus religiosa also reduced the migration as well as invasion capability of both cervical cancer cell lines accompanied with down-regulation of MMP-2 and Her-2 expression. In addition, italso reduced the expression of viral oncoproteins E6 and E7 in both cervical cancer cell lines [39-40].

\subsection{Gleditsia sinensis}

Gleditsia sinensisthorn extract decreased cell growth and increased cell cycle arrest during the G2/M-phase of colon cancer cells. The arrest was correlated with increased p53 levels and down-regulation of cyclinB1 [41].

\subsection{Glossostemon bruguieri}

The antiproliferative effects of moghat root extract and its apoptotic mechanism were investigated in hepatocellular carcinoma (HCC) cells, HepG2 and Hep3B. MTT assay, morphological changes, apoptosis enzyme linked immunosorbent assay, caspase and apoptotic activation, flow cytometry, and immunoblot analysis were employed. The IC $\mathrm{C}_{50}$ of moghat root extract for HepG2 was $910 \pm 6 \mu \mathrm{g} / \mathrm{ml}$ and for Hep3B was $1510 \pm 5 \mu \mathrm{g} / \mathrm{ml}$, it induced significant growth-inhibitory effects against

HCC cells, with no cytotoxic effect on normal hepatocytes. Moghat root extract treatment induced apoptotic effects to HepG2 cells in a caspase dependent manner and via up-regulating p53/p21 and PCNA. The upregulation of p21 was controlled by 553 expression in HepG2 but not in Hep3B despite up-regulation of Bax protein in both cell lines. P21 may be a remarkable switch to G1 arrest in HepG2 cells, but not in Hep3B cells. Furthermore, Fas- and mitochondriamediated pathways were found to be involved in moghat root extract -induced apoptosis in Hep3B cells [42-43].

\subsection{Hamelia patens}

Alkaloids: Rumberine, Alakaloid A, Isopteropodine, and Maruquine isolated from Hamelia patens were successfully dock inside the same active binding site of MDM2 protein where p53 peptide binds with a binding energy in a range of -7.42 to $-6.79 \mathrm{Kcal} / \mathrm{mol}$. Among the five tested compounds Palmirine has shown to be the best MDM2 inhibitor with a binding energy $-7.42 \mathrm{Kcal} / \mathrm{mol}$, whereas Maruquine compound showed the least binding affinity towards MDM2 with a binding energy $-6.79 \mathrm{kcal} / \mathrm{mol}[44]$.

\subsection{Hibiscus sabdariffa}

Human gastric carcinoma (AGS) cells were susceptible to Hibiscus polyphenol-rich extract $(0.95 \mathrm{mg} / \mathrm{ml} \mathrm{HPE} \mathrm{inhibited}$ its growth by 50\%). AGS cells underwent DNA fragmentation, and had an increase in the distribution of hypo diploid phase (apoptotic peak, 52.36\%) after a 24-h treatment with HPE (2.0 mg/ml). The effect of HPE on AGS cells might be mediated via p53 signaling and p38 MAPK/FasL cascade pathway, as demonstrated by an increase in the phosphorylation of p53 and the usage of a specific p38 inhibitor [45].

Hibiscus anthocyanins (Has) inhibited the serum-stimulated proliferation of smooth muscle cell (SMC) and resulted in cell apoptosis. The inducing cell apoptosis was dose dependent. HAs induced apoptosis via activating p38 MAP kinase that subsequently phosphorylates target protein c-Jun and transduces the signal to further activate the apoptotic protein cascades that contain Fas-mediated signaling (Fas/caspase-8 signaling module) and activating p53 and inducing bax expression [46-47].

\subsection{Juglans regia}

The effect of walnut green husk extracts on cell proliferation was evaluated on PC-3 human prostate cancer cells. Green husk extracts suppressed proliferation and induced apoptosis in a dose- and time dependent manner by modulating expression of apoptosis-related genes. This involved DNA fragmentation and significant changes in levels of mRNA and 
the expression of corresponding proteins. An increase in expressions of Bax, caspase-3, and tp53 genes and their corresponding proteins was detected using real-time PCR and western blot analysis in PC-3 cells treated with the green husk organic extracts. In contrast, Bcl2 expression was down regulated after exposure to the extracts [48].

The antiproliferative effect of root bark of Juglans regia (RBJR) organic extracts was studied in cell proliferation on MDAMB-231 human breast cancer cells. The results demonstrate that walnut root bark suppressed proliferation and induced apoptosis in a dose and time dependent manner by modulating expression of key genes. This involved characteristic changes in cytoplasmic and nuclear morphology, DNA fragmentation, levels of mRNA and expression of corresponding proteins. The expression of Bax, caspases, tp53, and TNF-alpha was markedly increased in MBA-MB-231 cells treated with the root bark extract. In contrast Bcl2 and mdm-2 expression was down regulated after exposure [49-50].

\subsection{Juniperus communis}

Imbricatolic acid isolated from the methanolic extract of the fresh ripe berries of Juniperus communis was evaluated for its ability to prevent cell cycle progression in p53-null CaLu-6 cells. It induced up-regulation of cyclin-dependent kinase inhibitors and their accumulation in the G1 phase of the cell cycle, as well as the degradation of cyclins A, D1, and E1[51].

The effects of juniper berry extract was evaluated on p53 protein, gene expression and DNA fragmentation in human neuroblastoma SH-SY5Y cells. The juniper berry extract activated cellular relocalization of p53 and DNA fragmentationdependent cell death. Differentially expressed genes between treated and non-treated cells were evaluated with the cDNA-RDA method at the early time point of apoptotic process when p53 started to be activated. Twenty one overexpressed genes related to cellular stress, protein synthesis, cell survival and death were detected. They included Endoplasmic Reticulum (ER) stress inducer and sensor HSPA5 and other ER stress-related genes CALM2 and YKT6 indicating that ER stress response was involved in juniper berry extract mediated cell death. The authors suggested that juniper berry extract induced the p53-associated apoptosis through the potentiation and synergism by several phenolic compounds [52-53].

\subsection{Lycium barbarum}

A preparation of a carotenoid nanoemulsion of Lycium barbarum was evaluated to know the mechanism of inhibition on HT-29 colon cancer cells. Both the carotenoid nanoemulsion and the extract were effective at inhibiting growth of HT-29 colon cancer cells, with IC 50 of 4.5 and $4.9 \mu \mathrm{g} / \mathrm{ml}$, respectively. Also, both treatments up-regulated p53 and p21 expression and down-regulated CDK2, CDK1, cyclin A and cyclin B expression and arrest the cell cycle at G2/M [54].

Crude hot water extract of Lycium barbarum (2-5 g/l) dose dependently inhibited proliferation of H-4-II-E cells and HA22T/VGH cells $(\mathrm{p}<0.01)$ after $24 \mathrm{~h}$. The apoptosis was significantly increased in H-4-II-E cells after $24 \mathrm{~h}$ treatment with higher doses of crude hot extract ( $2-5 \mathrm{~g} / \mathrm{l})(\mathrm{p}<0.01)$. The expression of p53 protein in H-4-II-E cells was $119 \%$ and $143 \%$ for 2 and $5 \mathrm{~g} / \mathrm{l}$ of hot extract of Lycium barbarum respectively, after $24 \mathrm{~h}$, compared with control group [55].

The anti-proliferative effect of Lycium barbarum polysaccharide (LBP, 0, 10, 30, 100, and $300 \mu \mathrm{g} / \mathrm{ml}$ for $24 \mathrm{~h}$.) was studied against MCF-7 cells. LBP arrested MCF-7 cell cycle in S phase. It also dose-dependently activated ERK, which may be associated with p53 pathway [56].

The hepatoprotective effects and mechanisms of LBP was studied in non-alcoholic steato-hepatitis (NASH)-induced hepatic injury in rat. Female rats were fed a high-fat diet to induce NASH with or without an oral $1 \mathrm{mg} / \mathrm{kg} \mathrm{LBP}$ daily for 8 weeks compared with control rats, NASH rats showed increase in liver injury, lipid content, fibrosis, oxidative stress, inflammation and apoptosis. In contrast, NASH+LBP-co-treated rats showed improving of histology and free fatty acid levels, re-balance of lipid metabolism, reduction in profibrogenic factors through the TGF- $\beta$ /SMAD pathway, improving of oxidative stress through cytochrome P450 2E1-dependent pathway, reduction in hepatic pro-inflammatory mediators and chemokines production and amelioration of hepatic apoptosis through the p53-dependent intrinsic and extrinsic pathways[57].

\subsection{Marrubium vulgare}

Marrubium vulgare ethanolic extract dose-dependently reduced viability of melanoma (B16) and glioma (U251) cells, but not peripheral blood mononuclear cells. It arrested cell cycle in S + G2/M phase, associated with activation of MAP kinase p38 and up-regulation of antiproliferative genes p53, p21 and p27. Marrubium vulgare ethanolic extract also induced mitochondrial depolarization, activation of caspase- 9 and -3 , Parp cleavage, phosphatidylserine exposure and DNA fragmentation. The mitochondrial apoptotic pathway was associated with the up-regulation of proapoptotic genes Pten, Bak1, Apaf1, and Puma and down-regulation of antiapoptotic genes survivin and Xiap. It also stimulated the 
expression of autophagy-related genes Atg5, Atg7, Atg12, Beclin-1, Gabarab and Sqstm1, as well as LC3-I conversion to the autophagosome associated LC3-II. The most abundant phenolic components of Marrubium vulgare ethanolic extract (ferulic, phydroxybenzoic, caffeic and chlorogenic acids), did not exert a profound effect on viability of tumor cells, suggesting that other components were responsible for its cytotoxicity [58-59].

\subsection{Momordica charantia}

The effects of Momordica charantia leaf extract and a purified component, Kuguacin J (KuJ), were investigated on androgen-dependent LNCaP human prostate cancer cells. Both treatments exerted growth inhibition through G1 arrest and induction of apoptosis. KuJ markedly decreased the levels of cyclins (D1 and E), cyclin-dependent kinases (Cdk2 and $\mathrm{Cdk} 4$ ) and proliferating cell nuclear antigen, and caused an increase in p21 and p27 levels. Its induction of apoptosis was accompanied by an increase in cleavage of caspase- 3 and poly (ADPribose) polymerase, attributed to augment of $\mathrm{Bax} / \mathrm{Bcl}-2$ and Bad/Bcl-xL and reduction of survivin levels. The extract and $\mathrm{KuJ}$ also reduced the expression of androgen receptor, prostate-specific antigen while induced P53 protein level. The extract and KuJ inhibited cell growth partly through p53-dependent cell cycle arrest and apoptotic pathways [60-61].

\subsection{Myrtus communis}

The ameliorate effect of Myrtus communis extract on the toxic effect of arsenic chloride $\left(\mathrm{AsCl}_{3}\right)$ on the production of the tumor suppressor protein (P53) was studied in rat. The results showed that AsCl3 induced negative effects on the P53based gene expression levels and probably the protein activity of P53 gene resulting in low gene expression, while, Myrtus communis improved the status by increasing the levels of P53- based gene expression if used alone or mixed with $\mathrm{AsCl}_{3}[62]$.

\subsection{Nigella sativa}

Thymoquinone inhibited doxorubicin-resistant human breast cancer MCF-7/DOX cell proliferation. It arrested MCF7/DOX cells at G2/M phase and increased cellular levels of p53 and p21 proteins. A significant increase in Sub-G1 cell population and appearance of DNA ladders were recorded with thymoquinone treatment, indicating cellular apoptosis. Thymoquinone - induced apoptosis was associated with disrupted mitochondrial membrane potential and activation of caspases and PARP cleavage in MCF-7/DOX cells. Furthermore, it increased Bax/Bcl2 ratio via up-regulating Bax and down-regulating Bcl2 proteins [63].

Human breast cancer cells (MCF-7) were treated with methanolic extract of Nigella sativa seeds, the IC 50 of the extract was $62.8 \mu \mathrm{l} / \mathrm{ml}$. When MCF-7 cells were exposed to 50 and $100 \mu \mathrm{l} / \mathrm{ml}$ extract for $24 \mathrm{~h}, 48 \mathrm{~h}$ and $72 \mathrm{~h}$, the investigation revealed a dose- and time dependent increase in apoptosis. In addition, the expression of the caspase- $3,-8,-9$ and p53 genes was increased significantly according to the dose and time [64].

The anti-tumor effects of thymoquinone have also been investigated in tumor xenograft mice models for colon, prostate, pancreatic and lung cancer. The combination of thymoquinone and conventional chemotherapeutic drugs produced greater therapeutic effect and reduced the toxicity of the chemotherapy. The anticancer effects of thymoquinone were mediated through different modes of action, including antiproliferation, apoptosis induction, cell cycle arrest, ROS generation and anti-metastasis/anti-angiogenesis. It also exhibited anticancer activity through the modulation of multiple molecular targets, including p53, p73, PTEN, STAT3, PPAR- $\gamma$, activation of caspases and generation of R0S [65].

The growth-suppression potentiality of a crude saponin extract of Nigella sativa was investigated against human colon cancer cells, HCT116. The extract inhibited proliferation and induced apoptosis (the extract-treated cells exhibited morphological hallmarks of apoptosis including cell shrinkage, irregularity in cellular shape, cellular detachment and chromatin condensation). The pro-apoptotic effect of the extract was caspase-3-independent and associated with increase of the Bax/Bcl-2 ratio. It down-regulated transcriptional and DNA-binding activities of NF- $\kappa \mathrm{B}$ and AP-1 proteins, associated with down-regulation of their target oncogenes, c-Myc, cyclin D1 and survivin. In addition, the extract up-regulated transcriptional and DNA-binding activities of Nrf2 and expression of cytoprotective genes. It also modulated the expression levels of ERK1/2 MAPK, p53 and p21 [66].

The anticancer effects of Nigella sativa extract was tested against human cervical cancer cells. The extract showed an $88.3 \%$ inhibition of proliferation of SiHa human cervical cancer cells at a concentration of $125 \mathrm{microl} / \mathrm{ml} \mathrm{methanolic}$ extract at $24 \mathrm{~h},\left(\mathrm{IC}_{50}\right.$ value was $\left.93.2 \mathrm{microl} / \mathrm{ml}\right)$. Extract exposure induced apoptosis in SiHa cell through both p53 and caspases activation [67]. 


\subsection{Olea europaea}

Oleuropein induced HeLa cells apoptosis as demonstrated by induction of a sub-G1 peak in flow cytometry and apoptosis-related morphological changes observed by fluorescence microscopy after being stained by Hoechst 33324 . The results also showed that $150-200 \mu \mathrm{M}$ oleuropein treated HeLa cells were arrested at the G2/M phase. The phosphorylated ATF-2, c-Jun NH2-terminal kinase (JNK) protein, p53, p21, Bax, and cytochrome c protein in the cytoplasm significantly increased in a dose dependent manner after treatment with oleuropein for $24 \mathrm{~h}$ [68].

\section{Conclusion}

Targeting the p53-MDM2 pathway can be a promising approach to develop compounds for cancer treatment and prevention. A number of natural products have been developed to target the p53-MDM2 pathway. The p53-MDM2 interactions have become the cornerstone of intensive cancer based research due to their effective anti-cancer properties. This review is an attempt to highlight the medicinal plants that can modulate the expression and activity ofp53tumor suppression, for cancer prevention and treatment.

\section{Compliance with ethical standards}

\section{Acknowledgments}

We acknowledged the dean of Thi Qar College of medicine for the scientific support.

\section{Disclosure of conflict of interest}

The authors confirm that this paper's content has no conflict of interests.

\section{References}

[1] Berger T, Saunders ME, Mak TW. Beyond the oncogene revolution: four new ways to combat cancer. Cold Spring Harb Symp Quant Biol. 2016; 81: 85-92.

[2] Sabapathy K. The contrived mutant p53 oncogene - beyond loss of functions. Front Oncol. 2015; 5: 276.

[3] Qin JJ, Li X, Hunt C, Wang W, Wang H, Zhang R. Natural products targeting the p53-MDM2 pathway and mutant p53: Recent advances and implications in cancer medicine. Genes \& Diseases. 2018; 5: 204-219.

[4] Joerger AC, Fersht AR. Structural biology of the tumor suppressor p53. Annu Rev Biochem. 2008; 77(1): 557582.

[5] Yue X, Zhao Y, Xu Y, Zheng M, Feng Z, Hu W. Mutant p53 in cancer: accumulation, gain-of-function, and therapy. J Mol Biol. 2017; 429(11): 1595-1606.

[6] Zhang C, Liu J, Xu D, Zhang T, Hu W, Feng Z. Gain-of-function mutant p53 in cancer progression and therapy. J Mol Cell Biol. 2020; 12(9): 674-687.

[7] Zhu G, Pan C, Bei JX, Li B, Liang C, Xu Y, Fu X. Mutant p53 in cancer progression and targeted herapies. Front Oncol. 2020; 10: 595187.

[8] Weinberg Robert A. The biology of cancer. J Chem Inf Model. 2013; 53: 1689-1699.

[9] Mello SS, Attardi LD. Deciphering p53 signaling in tumor suppression. Curr Opin Cell Biol. 2017; 51: 65-72.

[10] Ho T, Tan BX, Lane D. Does How the other half lives: What p53 when it is not being a transcription factor. Int J Mol Sci. 2020; 21(1): 13.

[11] Vogelstein B, Lane D, Levine AJ. Surfing the p53 network. Nature. 2000; 408: 307-310.

[12] Blagosklonny MV. P53: An ubiquitous target of anticancer drugs. International Journal of Cancer. 2002; 98: 161166.

[13] Blagosklonny MV. P53: An ubiquitous target of anticancer drugs. International Journal of Cancer. 2002; 98: 161166. 
[14] Raghavendra Rao MV, Vijay Raj B, Acharya Y, Kumar Nayak SJ, Sireesha Bala A, Pawar AS. Targeting p53-MDM2 interaction by natural plant products: A novel approach for future cancer therapy. Int J Life Sci Scienti Res. 2017; 3(2): 940-950.

[15] Hong YS, Ham YA, Choi JH et al. Effects of allyl sulfur compounds and garlic extract on the expression of Bcl-2, Bax, and p53 in non small cell lung cancer cell lines. Experimental and Molecular Medicine.2000; 32: 127-134.

[16] Al-Snafi AE. Pharmacological effects of Allium species grown in Iraq. An overview. International Journal of Pharmaceutical and health care Research. 2013; 1(4): 132-147.

[17] Abdel-Aziem SH, Hassan AM, El-Denshary ES, Hamzawy MA, Mannaa FA, Abdel-Wahhab MA. Ameliorative effects of thyme and calendula extracts alone or in combination against aflatoxins-induced oxidative stress and genotoxicity in rat liver. Cytotechnology.2014; 66(3): 457-470.

[18] Al-Snafi AE. The chemical constituents and pharmacological effects of Calendula officinalis - A review. Indian Journal of Pharmaceutical Science \& Research. 2015; 5(3): 172-185.

[19] Ito K, Nakazato T, Yamato K, Miyakawa Y, Yamada T, Hozumi N, Segawa K, Ikeda Y, Kizaki M. Induction of apoptosis in leukemic cells by homovanillic acid derivative, capsaicin, through oxidative stress: implication of phosphorylation of p53 at Ser-15 residue by reactive oxygen species. Cancer Res. 2004; 64: 1071-1078.

[20] Al-Snafi AE. The pharmacological importance of Capsicum species (Capsicum annuum and Capsicum frutescens)grown in Iraq. Journal of Pharmaceutical Biology. 2015; 5(3): 124-142.

[21] Lian ZQ, Zhao DL, Zhu HB. Hydroxysafflor yellow A up-regulates HIF-1alpha via inhibition of VHL and p53 in Eahy 926 cell line exposed to hypoxi. Yao Xue Xue Bao. 2008; 43(5): 484-489.

[22] Al-Snafi AE. The chemical constituents and pharmacological importance of Carthamus tinctorius - An overview. Journal of Pharmaceutical Biology. 2015; 5(3): 143-166.

[23] Onyango TB, Hjelle SM, Haaland I, Vintermyr OK, Johannessen AC, Gjertsen BT. A Comparison of p53 Isoform Profiles and Apoptosis Induced by Camptothecin or a Herbal Khat Extract (Catha Edulis (Vahl) Forssk. ex Endl.) in Leukemic Cell Lines: Exploring Cellular Responses in Therapy Development. Cancers (Basel). 2020 Dec 1; 12(12): 3596.

[24] Patil JR. Studies on isolation and characterization of bioactive compoundsin lime [Citrus aurantifolia (Christm) Swingle], their antioxidant and anticancer properties. PhD thesis, University of Agricultural Sciences, Dharwad. 2009.

[25] Al-Snafi AE. Nutritional value and pharmacological importance of citrus species grown in Iraq. IOSR Journal of Pharmacy. 2016; 6(8): 76-108.

[26] Chen JC, Chang NW, Chung JG, Chen KC. Saikosaponin-A induces apoptotic mechanism in human breast MDA-MB231 and MCF-7 cancer cells. Am J Chin Med. 2003; 31(3): 363-377.

[27] Al-Snafi AE. The constituents and pharmacology of Corchorus aestuans: A review. The Pharmaceutical and Chemical Journal. 2016; 3(4): 208-214.

[28] Bajbouj K, Schulze-Luehrmann J, Diermeier S, Amin A, Schneider-Stock R. The anticancer effect of saffron in two p53 isogenic colorectal cancer cell lines. BMC Complement Altern Med.2012; 12: 69-78.

[29] Al-Snafi AE.The pharmacology of Crocus sativus- A review. IOSR Journal of Pharmacy. 2016; 6(6): 8-38.

[30] Xia D. Ovarian cancer HO-8910 cell apoptosis induced by crocin in vitro. Nat Prod Commun. 2015; 10(2): 249252.

[31] Pal K, Laha D, Parida PK, et al. An in vivo study for targeted delivery of curcumin in human triple negative breast carcinoma cells conjugated with folic acid. J Nanosci Nanotechnol. 2018; 18: 1-14.

[32] Bimonte S, Barbieri A, Palma G. Dissecting the role of curcumin in tumour growth and angiogenesis in mouse model of human breast cancer. Biomed Res Int. 2015; 878134.

[33] Shebaby WN, Bodman-Smith KB, Mansour A, Mroueh M, Taleb RI, El-Sibai M, Daher CF. Daucus carota pentanebased fractions suppress proliferation and induce apoptosis in human colon adenocarcinoma HT-29 cells by inhibiting the MAPK and PI3K pathways. J Med Food. 2015; 18(7): 745-752.

[34] Al-Snafi AE. Nutritional and therapeutic importance ofDaucus carota- A review. IOSR Journal of Pharmacy. 2017; $7(2): 72-88$. 
[35] Al-Snafi AE. Phytochemical constituents and medicinal properties of Digitalis lanata and Digitalis purpurea - A review. Indo Am J P Sci. 2017; 4(02): 225-234.

[36] Al-Snafi AE. Foxglove (Digitalis purpurea and Digitalis lanata). In: Medicinal Plants in India, Importance and Cultivation. Edited by: SN Ghosh, A Nath andP Bakshi. Jaya Publishing House, Delhi-India. 2019; 178-202.

[37] Islam F,Khanam JA, Khatun M, Zuberi N, Khatun L, Kabir, Md Abu Reza SR, Ali MM,Rabbi MA, Gopalan V, Lam AKY. A $p$-Menth-1-ene-4,7-diol (EC-1) from Eucalyptus camaldulensis Dhnh. Triggers apoptosis and cell cycle changes in Ehrlich ascites carcinoma cells. Phytotherapy Research. 2015; 29(4):573-581.

[38] Al-Snafi AE.The pharmacological and therapeutic importance of Eucalyptus species grown in Iraq.IOSR Journal of Pharmacy. 2017; 7(3): 72-91.

[39] Choudhari AS, Suryavanshi SA, Kaul-Ghanekar R. The aqueous extract of Ficus religiosa induces cell cycle arrest in human cervical cancer cell lines SiHa (HPV-16 Positive) and apoptosis in HeLa (HPV-18 positive). PLoS One.2013; 8(7): e70127.

[40] Al-Snafi AE. Pharmacology of Ficus religiosa- A review. IOSR Journal of Pharmacy. 2017; 7(3): 49-60.

[41] Lee SJ, Park K, Ha SD, Kim WJ, Moon SK. Gleditsia sinensis thorn extract inhibits human colon cancer cells: the role of ERK1/2, G2/M-phase cell cycle arrest and p53 expression. Phytotherapy Research. 2010; 24(12); 1870- 1876.

[42] Alwhibi MS, Khalil MIM, Ibrahim MM, El-Gaaly GA, Sultan AS. Potential antitumor activity and apoptosis induction of Glossostemon bruguieri root extract against hepatocellular carcinoma cells. Evid Based Complement Alternat Med 2017; 7218562.

[43] Al-Snafi AE. Medical importance of Glossostemon bruguieri - A review. IOSR Journal of pharmacy. 2019; 9(5): 3439.

[44] Raghavendra Rao MV, Vijay Raj B, Acharya Y, Kumar Nayak SJ, Sireesha Bala A, Pawar AS. Targeting p53-MDM2 interaction by natural plant products: A novel approach for future cancer therapy. Int J Life Sci Scienti Res. 2017;3(2): 940-950.

[45] Lin HH, Huang HP, Huang CC, Chen JH, Wang CJ. Hibiscus polyphenol-rich extract induces apoptosis in human gastric carcinoma cells via p53 phosphorylation and p38 MAPK/FasL cascade pathway. Mol Carcinog. 2005; 43(2): 86-99.

[46] Lo CW, Huang HP, Lin HM, Chien CT, Wang CJ. Effect of hibiscus anthocyanins-rich extract induces apoptosis of proliferating smooth muscle cell via activation of P38 MAPK and p53 pathway. Mol Nutr Food Res. 2007; 51(12): 1452-1460.

[47] Al-Snafi AE. Pharmacological and therapeutic importance of Hibiscus sabdariffa- A review. International Journal of Pharmaceutical Research. 2018; 10(3): 451-475.

[48] Alshatwi AA, Hasan TN, Shafi G, Syed NA, Al-Assaf AH, Alamri MS, Al-Khalifa AS. Validation of the Antiproliferative effects of organic extracts from the green husk of Juglans regia L. on PC-3 human prostate cancer cells by assessment of apoptosis-related genes. Evid Based Complement Alternat Med 2012; 103026.

[49] Hasan TN, B LG, Shafi G, Al-Hazzani AA, Alshatwi AA. Antiproliferative effects of organic extracts from root bark of Juglans regia L. (RBJR) on MDA-MB-231 human breast cancer cells: roleof Bcl-2/Bax, caspases and Tp53. Asian Pac J Cancer Prev. 2011; 12(2): 525-530.

[50] Al-SnafiAE.Chemical constituents, nutritional, pharmacological and therapeutic importance of Juglans regia- A review. IOSR Journal of Pharmacy. 2018; 8(11): 1-21.

[51] De Marino S, Cattaneo F, Festa C, Zollo F, Iaccio A, Ammendola R, Incollingo F, Iorizzi M. Imbricatolic acid from Juniperus communis L. prevents cell cycle progression in CaLu-6 cells. Planta Med. 2011; 77(16):1822-1828.

[52] Lantto TA, Laakso I, Dorman HJ, Mauriala T, Hiltunen R, Kõks S, Raasmaja A. Cellular stress and p53-associated apoptosis by Juniperus communis L. berry extract treatment in the human SHSY5Y neuroblastoma cells. Int J Mol Sci.2016; 17(7): pii: E1113.

[53] Al-Snafi AE.Medical importance of Juniperus communis - A review. Indo Am J P Sc. 2018; 5(3): 1979-1792.

[54] Hsu HJ, Huang RF, Kao TH, Inbaraj BS, Chen BH. Preparation of carotenoid extracts and nanoemulsions from Lycium barbarum L. and their effects on growth of HT-29 colon cancer cells. Nanotechnology. 2017; 28(13): 135103. 
[55] Chao JC, Chiang SW, Wang CC, Tsai YH, Wu MS. Hot water- extracted Lycium barbarum and Rehmannia glutinosa inhibit proliferation and induce apoptosis of hepato cellular carcinoma cells. World J Gastroenterol. 2006; 12(28): 4478- 4484.

[56] Shen L, Du G. Lycium barbarum polysaccharide stimulates proliferation of MCF-7 cells by the ERK pathway.Life Sci. 2012; 91(9-10): 353-357.

[57] Xiao J, Liong EC, Ching YP, Chang RC, Fung ML, Xu AM, So KF, Tipoe GL. Lycium barbarum polysaccharides protect rat liver from non-alcoholic steatohepatitis-induced injury. Nutr Diabetes. 2013; 3: e81.

[58] Paunovic V, Kosic M, Djordjevic S, Zugic A, Djalinac N, Gasic U, Trajkovic V, Harhaji-Trajkovic J. Marrubium vulgare ethanolic extract induces proliferation block, apoptosis, and cytoprotective autophagy in cancer cells in vitro. Cell Mol Biol (Noisy-le-grand). 2016; 62(11):108-114.

[59] Al-Snafi AE.Al-Saedy HA, Talab TA, Majid WJ, El-Saber Batiha G, Jafari-Sales Abolfazl.The bioactive ingredients and therapeutic effects of Marrubium vulgare - A review. International Journal of Biological and Pharmaceutical Sciences Archive. 2021; 1(2):9-21.

[60] Pitchakarn P, Suzuki S, Ogawa K, Pompimon W, Takahashi S, Asamoto M, Limtrakul P, Shirai T. Induction of G1 arrest and apoptosis in androgen-dependent human prostate cancer by Kuguacin J, a triterpenoid from Momordica charantia leaf. Cancer Lett. 2011; 306(2): 142-150.

[61] Pitchakarn P, Suzuki S, Ogawa K, Pompimon W, Takahashi S, Asamoto M, Limtrakul P, Shirai T. Kuguacin J, a triterpeniod from Momordica charantia leaf, modulates the progression of androgen-independent human prostate cancer cell line, PC3. Food Chem Toxicol. 2012; 50(3-4): 840-847.

[62] Naji HA, Rhiyf AG, Al-Zebeeby A. Protective features of Myrtus communis leaves against the genotoxic effects of arsenic in wistar rats. J Pharm Sci \& Res. 2018; 10(11): 2921-2923.

[63] Arafa elSA, Zhu Q, Shah ZI, Wani G, Barakat BM, Racoma I. Thymoquinone upregulates PTEN expression and induces apoptosis in doxorubicin resistant human breast cancer cells. MutatRes 2011; 706: 28-35.

[64] Alhazmi MI, Hasan TN, Shafi G, Al-Assaf AH, Alfawaz MA, Alshatwi AA. Roles of p53 and caspases in induction of apoptosis in MCF- 7 breast cancer cells treated with a methanolic extract of Nigella sativa seeds. Asian Pac J Cancer Prev. 2014; 15(22): 9655-9660.

[65] Woo CC, Kumar AP, Sethi G, Tan KH. Thymoquinone: potential cure for inflammatory disorders and cancer. Biochem Pharmacol. 2012; 83(4): 443-451.

[66] Elkady AI, Hussein RA and El-Assouli SM. Mechanism of action of Nigella sativa on human colon cancer cells: the suppression of AP-1 and NF- $\mathrm{KB}$ transcription factors and the induction of cytoprotective Genes. Asian Pac J Cancer Prev. 2015; 16(17): 7943- 7957.

[67] Hasan TN, Shafi G, Syed NA, Alfawaz MA, Alsaif MA, Munshi A, Lei KY, Alshatwi AA. Methanolic extract of Nigella sativa seed inhibits SiHa human cervical cancer cell proliferation through apoptosis. Nat Prod Commun. 2013; 8(2): 213-216.

[68] Yao J, Wu J, Yang X, Yang J, Zhang Y, Du L. Oleuropein induced apoptosis in HeLa cells via a mitochondrial apoptotic cascade associated with activation of the c-Jun NH2 - terminal kinase. J Pharmacol Sci. 2014; 125(3): 300-311. 